\title{
Design-Based Learning Model and Senior Secondary Students' Learning Achievement in Solid Geometry
}

\author{
Wonu, Nduka \\ Department of Mathematics/Statistics \\ Faculty of Natural and Applied Sciences \\ Ignatius Ajuru University of Education, Port Harcourt, Nigeria. \\ Arokoyu, Abosede Ajoke (Ph.D) \\ Department of Curriculum Studies and Educational Technology \\ Faculty of Education, University of Port Harcourt
}

doi: 10.19044/esj.2016.v12n34p272 URL:http://dx.doi.org/10.19044/esj.2016.v12n34p272

Abstract:

This study is an exploration of the effectiveness of Design-Based Learning (DBL) model in the improvement of senior secondary students' achievement in solid geometry in Emohua Local Government Area of Rivers State. The quasi-experimental design was adopted. A sample of 59 Senior Secondary School I (SSSI) students took part in the study. Solid Geometry Achievement Test (SGAT) was the instrument used for data collection. The Kuder-Richardson KR-21 method was used to establish the reliability of SGAT to obtain an index of 0.84 . Two research questions and two null hypotheses guided the study. The research questions were answered using mean and standard deviation while the hypotheses were tested using Analysis of Covariance (ANCOVA) at .05 level of significance. The findings established that DBL model was superior to Problem-based Learning (PbL) model in advancing the learning achievement of students in solid geometry. The students of both groups improved in learning over time with higher learning gain among students in the experimental group. The male and the female students in the experimental group outperformed their counterparts in the control group over SGAT scores. The male and the female students taught using the DBL and PbL respectively did not significantly differ over SGAT scores. It was recommended among others that mathematics teacher should apply the DBL in teaching solid geometry in the senior secondary schools in Nigeria because when effectively utilized, this instructional model 
is capable of advancing the learning achievement of students in mathematics irrespective of their locations and gender

Keywords: Design-based learning model, Learning achievement, Solid geometry

\section{Introduction}

Mathematics is the foundation for science and technology and the functional role of mathematics to science and technology is multifarious, that no other area of science, technology and business enterprise escapes its application. Mathematics is the science of things that have a pattern of regulatory, logical order, findings and exploring the regularity (Okereke, 2006). Besides its importance it is observed that mathematics is one of the most poorly taught, widely hated and abysmally understood subject in elementary schools. Students' poor performance in mathematics can be attributed to factors such as society view that mathematics is difficult, shortage of qualified teachers, lack of mathematics laboratory and lack of attractiveness and novelty in teaching method. Therefore merely telling is not teaching and simply listening is not learning. The students become passive receivers of information in a traditional model of teaching. In this period of unparalleled advancement in technology and steady change in all spheres of human endeavour, stakeholders in education are confronted more than ever with the need to make the learners to be adaptable in this speedy metamorphosing environment. This beckons the need to equip the students with better learning abilities and thinking skills aimed at the improvement of skills in terms of enterprise and creativity (Seng, 2001).

The modern system of education is the student-centered learning process which places the teacher as a facilitator or guide who aids the students to become independent thinkers through real life problem-solving exercise. Tick (2007) indicated that in student centred learning, setting the student is the central figure of the teaching-learning process of any desirable problem based learning episode. The overarching objective of the learning is not the recall or reproduction of the learning of the material received passively but the creative and active engagement of the learners in teamwork and/or independent learning to instill the transfer of knowledge and skills. The freedom of personal and conscious decision on the duration of learning and learning strategy is an advantage of self-directed learning. Orhan \& Ruhan, (2007) established that in all active learning process, the learner learns according to personal needs and pace. The need to engage the learners in critical-thinking exercise to make them independent thinkers while engaging in design science project steers the discourse to the need to adopt 
the Design-Based Learning (DBL) model which has been proven to improve students understanding of science content and enhance learners independence in reasoning.

Design-Based Learning (DBL) model is a form of Project-Based Learning (PBL) model in which students learn what they need to learn in a just-in-time fashion while trying to design something (Apedoe, Ellefson \& Schunn 2012). The DBL is a unique type of PBL (Barron, et al 1998). This instructional model is a combination of engineering design and scientific enquiry in a united effort for the engagement of learners to reason scientifically through solving real-life practical problems. It enhances the interest of students and ignites their passion towards science. (Apedoe, Reynolds, Ellefson, \& Schunn, 2008). Researchers in education are now reassessing the optional models for the meeting point between inquiry and design in science sessions. The students in DBL learning environment are made to identify and apply theoretical knowledge while finding solutions to their design task. The overarching goal of the DBL model is design of projects, solutions and systems in a PBL setting. (Lewis 2006, Kolodner, 2002; Lee \& Breitenberg, 2010; Apedoe \& Schunn, 2012).

Apedoe et al (2008) investigated the efficacy of DBL in teaching heating./cooling unit in chemistry. The findings of the study among others revealed that students engaged in DBL made a significant improvement in the understanding of the units taught. The DBL successfully led to increased interest and awareness in engineering career among high school students who participated in the study. The study provided an empirical evidences that DBL can be a useful instructional model for teaching difficult core concept in chemistry. Apedoe et al (2012) investigation was geared toward the examination of strategies groups of students instinctively adopt to unravel the solution to a prototypical design science problem, as well as to establish the relative value of these strategies for the achievement of success in design and the learning of design principles. The results of the study among others showed that learners adopt both design-based and science reasoning strategies. The strategies basically linked with success in science were found not to lead to success in design. Irrespective of the fact that both design-based and science strategies led to learning of the content, the content learned was not the same. Doppelt, Mehalik, Schunn, Silk, \& Krysinski (2008) investigated the engagement and achievement of students in a DBL science setting. The study revealed that students advanced in their knowledge of the concepts taught. The students were engaged in DBL session. The low achieving students also improved in learning scientific concepts. The students gained deep experience of the design task and developed projects. The DBL proved to have the potential to enhance the interest and success of students in science classroom. There is also the need 
to consider the impact of gender on the learning achievement of students adopting DBL in a science classroom setting.

Mehalik, Doppelt, and Schunn (2008) compared DBL versus scripted inquiry over students science concept learning and equity gap reduction. The findings revealed among others that DBL group improved in achievement in core science concept, engagement and retention than those who adopted the scripted inquiry approach. Low achieving African Americans benefited most from the DBL activities. The male students in adopting the DBL model had significant gains in learning in comparison to their counterparts who used scripted inquiry model. The male and the female students in the DBL group had nearly identical mean learning gain, showing that the DBL model does not yield any gender-based achievement gaps. The achievement gains of the female students was higher for the DBL model however, there was no significant difference in the science achievement scores between the male and the female students in DBL group. Silk, Schunn and Cary (2009) explored the efficacy of engineering design in advancing science reasoning among students in a high-need urban setting. The DBL applied the scaffolds in the construction of a design solution for the satisfaction of a specific need in everyday endeavours. This offered a meaningful setting where learners could be engaged to reason scientifically. The result of this study showed that students who participated in the design science episode improved significantly in their reasoning abilities. The study further established among others that gender was not a statistically significant factor in the prediction of the reasoning ability of students. Therefore, the need to conduct a study on the efficacy of DBL in the improvement of the learning achievement of students in mathematics is worthwhile and timely.

\section{Statement of the Problem}

The underachievement of students in mathematics has become a recurring decimal. The abysmal performance of the students in mathematics has been linked with several factors including mathematics anxiety and poor teaching among others. Mathematics teachers' indifference towards engaging the students in real-life mathematical laboratory activities has remained a problem as most of them still use lecture method that has not changed in decades. The scientific and technological development of the nation will be a mirage unless something drastic is done to revolutionize the instructional model adopted by the mathematics teachers in the schools and bring in innovative learning models that are capable of advancing the learning of the students in mathematics. A broad range of explorations have been conducted to improve students achievement in mathematics to enable them apply this acquired knowledge in solving real life practical problems. These studies did 
not involve the students in the design of artifacts or projects while solving practical problems in mathematics and most of the studies that involved students in DBL science projects were done outside Nigeria. The critical thinking competency of the senior secondary students for solving tasking real life problem is uncertain. Therefore the present study is planned to ignite the passion of the students for participation in mathematics design projects and challenge them to solve real life problems while engaging in design projects. Therefore this study investigates the effectiveness of DBL model for enhancing the achievement of senior secondary students in solid geometry in the in Emohua Local Government Area (LGA) of Rivers State.

\section{Aim and objectives of the study}

This study investigated the effectiveness of Design-Based Learning in the improvement of the learning achievement of students in solid geometry in Emohua LGA of Rivers State of Nigeria. Specifically, the present exploration intends to:

1. investigate the effect of DBL model on the learning achievement of senior secondary students in solid geometry;

2. determine the main effects of sex on the learning achievement of students taught solid geometry using DBL and those taught using Problembased Learning (PbL) model

\section{Research questions}

The following research questions guided the study

1. What is the effect of Design-Based Learning (DBL) model on the learning achievement of senior secondary students in solid geometry?

2. What is the relative main effect of sex on the learning achievement of students taught solid geometry using DBL and those taught using Problembased Learning (PbL) model?

\section{Hypotheses}

The following research hypotheses were tested at 0.05 alpha level.

$\mathbf{H}_{\mathbf{0 1}}$ : There is no significant effect of Design-Based Learning model on the learning achievement of senior secondary students in solid geometry.

$\mathbf{H}_{\mathbf{0 2}}$ : There is no significant relative main effect of sex on the learning achievement of students taught solid geometry using DBL and those taught using PbL model.

\section{Methodology \\ Design of the study}

The study adopted quasi-experimental design. The independent variable of the study was instructional model. The dependent variable was 
students' learning achievement in solid geometry. The symbolic representation of the research design of the study is illustrated on Table 1:

Table .1: Quasi-experimental research design

\begin{tabular}{cccc}
\hline Group & Pre-test & Treatment & Post-test \\
\hline E & $\mathrm{O}_{1}$ & $\mathrm{X}_{\mathrm{D}}$ & $\mathrm{O}_{2}$ \\
$\mathrm{C}$ & $\mathrm{O}_{1}$ & $\mathrm{X}_{\mathrm{p}}$ & $\mathrm{O}_{2}$ \\
\hline
\end{tabular}

Where:

$\mathrm{O}_{1}=$ Solid geometry achievement pre-test, $\mathrm{O}_{2}=$ Solid geometry achievement post-test,

$\mathrm{E}=$ Experimental group,

$\mathrm{C}=$ Control group

$$
\begin{aligned}
& \mathrm{X}_{\mathrm{D}}=\text { Design-Based Learning }(\mathrm{DBL}) \\
& \mathrm{X}_{\mathrm{p}}=\text { Problem based learning }(\mathrm{PbL})
\end{aligned}
$$

\section{Population, Sample and sampling technique}

A total of 2190 public Senior Secondary School one (SSS1) students in Emohua Local Government Area of Rivers State (Rivers State Senior Secondary Schools Board, 2015) is the population of the study. A sample of 59 SSS1 students took part in the study. The purposive sampling technique was used to select Emohua LGA from the 23 LGAs in Rivers State. The criteria for selecting the schools includes (1) being a public school (2) coeducational (3) solid geometry must not have been taught in the school (4) entrance for the SSCE exams by the schools.

\section{Instrumentation}

Solid Geometry Achievement Test (SGAT) was used for data collection. The instrument had 50 multiple-choice items with four options lettered A to D to be marked over 100. The SGAT was based on five content areas in solid geometry for SSS1 students, viz: volume and total surface area of solid shapes, frustum of pyramid and cone and composite solids. The instrument was validated by the researchers and some experts in measurement and evaluation and mathematics education. Kuder-Richardson KR-21 reliability method was used to establish the reliability of the instrument to obtain an index of 0.84 .

\section{Method of data collection}

The Pre-SGAT and Post-SGAT were done by specially briefed teachers. The scripts from the Pre-SGAT were collected before the commencement of the appropriate lesson by the teacher. The researchers gave the teachers training on the practical and the theoretical aspects of DBL instructional model and PbL instructional models for two days. Prior to the instructions in the two groups, Pre-SGAT was administered to the students and the students were given 45 minutes to attempt the questions. The PreSGAT scripts were retrieved from the students when completed. By the end 
of the instructions, Post-SGAT was administered and retrieved from the students.

Experimental group: The students in the experimental group were instructed using the DBL model. The students worked in groups, sharing ideas, knowledge and helping one another in small groups. Eight (8) learning cycle phases (Create design, Evaluate outcome, Generate reasons, Test idea, Analyze Results, Generalize Results, Connect to Big Idea) or strategic components of the strategy formed the objectives of the study. The students were engaged in the prototypical development of projects using relevant instructional materials while the teacher served as a facilitator, asking questions to trigger critical thinking skills among groups of participants. The cycle commenced in create a design and ended in connect to big idea phase.

Control group: The students in the control group adopted the $\mathrm{PbL}$ model. They also worked on the same solid geometry content. The teacher posed the problems on the chalkboard, teach the large class of students to solve the problem while paying attention. The teacher also directs the students to solve problems in the class following five (5) specific key instructional objectives which formed the strategic components (Study, Planning, Execution, Evaluation, Development) of the PbL model.

\section{Data analysis}

The mean and Standard Deviation (SD) were used to answer the research questions while Analysis of Covariance (ANCOVA) was used to test the hypotheses at 0.05 level of significance.

\section{Rsults}

Table 2 Mean, standard deviation and gain SGAT score of groups of students taught using DBL and PbL.

\begin{tabular}{cccccccccc}
\hline & & Pretest & \multicolumn{3}{c}{ Posttest } & \multicolumn{3}{c}{ Gain } & \multicolumn{2}{c}{$95 \%$ CI } \\
Model & $\mathrm{N}$ & $\overline{\mathrm{X}}$ & $\mathrm{SD}$ & $\overline{\mathrm{X}}$ & SD & $\overline{\mathrm{X}}$ & SD & LB & UB \\
\hline DBL & 29 & 30.83 & 8.87 & 61.10 & 7.76 & 30.28 & 11.36 & 25.95 & 34.60 \\
PbL & 30 & 26.73 & 5.72 & 48.60 & 8.16 & 21.87 & 10.54 & 17.93 & 25.80 \\
\hline
\end{tabular}

Key: LB=Lower Bound (for gain scores), UB=Upper Bound (for gain scores), SD=Standard deviation, $\mathrm{CI}=95 \%$ Confidence Interval, $\mathrm{N}=$ Number of participants in each group

Table 2 shows that the mean gain of students taught solid geometry with DBL was $30.28 \pm 11.36$. The $95 \%$ confidence interval was found to move from 25.95 to 34.60 . The mean SGAT gain score of students taught using $\mathrm{PbL}$ was $21.87 \pm 10.54$ whereas the $95 \%$ confidence interval moved from 17.93 to 25.80 . 
Table 3: Mean, standard deviation and SGAT gain score of groups of the male and the female students taught using DBL and PbL

\begin{tabular}{|c|c|c|c|c|c|c|c|c|c|c|}
\hline \multirow[b]{2}{*}{ Model } & \multirow[b]{2}{*}{ Sex } & \multicolumn{3}{|c|}{ Pretest } & \multirow{2}{*}{$\begin{array}{c}\text { Posttest } \\
\overline{\mathrm{X}}\end{array}$} & \multicolumn{3}{|c|}{ Gain } & \multicolumn{2}{|c|}{$95 \%$ CI } \\
\hline & & $\mathrm{N}$ & $\bar{X}$ & SD & & SD & $\bar{X}$ & SD & LB & UB \\
\hline \multirow[t]{2}{*}{ DBL } & Male & 16 & 29.25 & 6.73 & 62.75 & 8.48 & 33.50 & 9.76 & 28.30 & 38.70 \\
\hline & Female & 13 & 32.77 & 10.94 & 59.08 & 6.51 & 26.31 & 12.30 & 18.88 & 33.74 \\
\hline \multirow[t]{2}{*}{$\mathrm{PbL}$} & Male & 12 & 27.67 & 5.10 & 46.50 & 8.99 & 18.83 & 12.69 & 10.77 & 26.90 \\
\hline & Female & 18 & 26.11 & 6.15 & 50.00 & 7.48 & 23.89 & 8.64 & 19.59 & 28.18 \\
\hline
\end{tabular}

Table 3 shows that the mean SGAT gain score of the male students taught using DBL was $33.50 \pm 9.76$ with the $95 \%$ confidence interval moving from 28.30 to 38.70 whereas the mean SGAT gain score of the female students taught using DBL was $26.31 \pm 12.30$ with the $95 \%$ confidence interval moving from 18.88 to 33.74. Table 5 further showed that the mean SGAT gain score of the male students taught using PbL was $18.83 \pm 12.69$ with the $95 \%$ confidence interval moving from 10.77 to 26.90 whereas the mean SGAT gain score of the female students taught using DBL was 23.89 \pm 8.64 with the $95 \%$ confidence interval moving from19.59 to 28.18 .

Table 4A: Summary of ANCOVA on SGAT scores based on treatment and sex

\begin{tabular}{ccccccc}
\hline Source & SS & df & MS & F & p-value & $\eta^{2}$ \\
\hline Pre-SGAT & .381 & 1 & .381 & .006 & .940 & .000 \\
Treatment & 2091.782 & 1 & 2091.782 & 31.839 & .000 & .367 \\
Sex & .068 & 1 & .068 & .001 & .974 & .000 \\
Error & 3613.418 & 55 & 65.699 & & & \\
Total & 182748.000 & 59 & & & & \\
Corrected Total & 5919.186 & 58 & & & & \\
\hline
\end{tabular}

a. R Squared $=.390$ (Adjusted R Squared $=.356$ )

$\mathrm{SS}=$ Type III Sum of Squares, $\mathrm{df}=$ Degree of freedom, MS=Mean Square

The result on Table 4A indicated that there was a significant main effect of DBL model on the SGAT scores of students $(F=1,55=31.839$, $\left.\mathrm{p}=.000, \eta^{2}=.367\right)$. The null hypothesis one was rejected at .05 alpha level. Table 4A further indicated that there was no significant relative main effect of sex on the learning achievement of students taught solid geometry using DBL and those taught using PbL model(F1, 55=.001, p=.974, $\eta^{2}=.000$ ). The null hypothesis two was upheld at .05 alpha level. This above result was further simplified on Table 4B using simple main effects of sex on the SGAT scores of the students.

Table 4B: Simple-main effect analysis on SGAT scores

\begin{tabular}{cccccccc}
\hline & Independent variable & SS & df & MS & F & p-value & $\eta^{2}$ \\
\hline \multirow{2}{*}{ Sex } & DBL & 113.245 & 1 & 113.245 & 1.884 & .182 & .068 \\
& PbL & 75.850 & 1 & 75.850 & 1.124 & .298 & .040 \\
\hline
\end{tabular}


Part $\mathrm{B}$ of Table 4B further shows that the male and the female students taught using the DBL $\left(\mathrm{F}=1.884, \mathrm{p}=.182, \eta^{2}=.068\right)$ and $\mathrm{PbL}$ $\left(\mathrm{F}=1.124, \mathrm{p}=.298, \eta^{2}=.040\right)$ respectively did not significantly differ over SGAT scores. This further substantiated the result on Part A of Table 4 above.

\section{Discussion Of Findings}

The discussion of the key findings of the present study was done under the following sub-headings:

\section{Design-Based Learning and the learning achievement of students in solid geometry}

The result from Table 2 shows that the variance between the experimental group and the control group over Post-SGAT mean scores was 12.5 whereas the mean difference between both groups over gain in SGAT was 8.41. Both differences were in favour of the experimental group who were taught using DBL. This substantiates the efficacy of the DBL group over PBL in the improvement of the learning achievement of the students in solid geometry. The observed mean difference between the experimental and control groups over gain SGAT scores which favoured the experimental group may have been because those who participated in the experimental group had the opportunity to interact in groups, shared ideas, involved in critical thinking activities and solved real life mathematical problems in an engaging and authentic way in comparison with their counterparts who observed the teachers approach and tried to solve the problems independently.

The statistical test from Part A of Table 4 shows that there was significant main effect of DBL model on the SGAT scores of students $(F=1$, $\left.55=31.839, \mathrm{p}=.000, \eta^{2}=.367\right)$. The null hypothesis one was rejected at .05 alpha level. This result is consistent with earlier findings by Silk et al (2009) which established the efficacy of design science curriculum in the improvement of learners reasoning. The study reported that participants in the design science demonstrated statistically significant improvement on their test scores over time. The findings showed that DBL compared favourably with a traditional textbook curriculum and inquiry science of high-quality. This further substantiates the implication for the use of DBL as an alternative instructional model for teaching mathematics in the rural schools. 


\section{Design-Based Learning and gender associated differences in the learning achievement of students in solid geometry}

The results from Table 3 established that the Post-SGAT mean difference between the male and the female students in the experimental group was 3.67 in favour of the male students. The variance in the mean SGAT gain scores between the male and the female students was 7.19 also in favour of the male students who adopted DBL model. Divergently, the PostSGAT mean difference between the male and the female students who participated in the control group was 3.50 in favour of the female students. Also, the discrepancy in the mean SGAT gain scores between the male and the female students was 5.06 in favour of female students who were instructed using the $\mathrm{PbL}$ instructional model. A closer peer at the Table 3 also revealed that the male and the female students of the experimental group respectively outperformed their counterparts in the control group in all aspects of the test. This result showed that the male students may have interacted among themselves more than their female counterparts during the design science or project development activities. This may have given them the opportunity to ask questions on their areas of difficulties and clear their doubts, thus the higher score over their female counterparts. The result of the statistical test shown on Part A of Table 4 revealed that there was no significant relative main effect of sex on the learning achievement of students taught solid geometry using $\mathrm{DBL}$ and those taught using $\mathrm{PbL}$ model(F1, 55=.001, $\left.\mathrm{p}=.974, \eta^{2}=.000\right)$. The null hypothesis two was upheld at .05 alpha level. The Part B of Table 4 specifically established that the male and the female students instructed using the DBL $\left(F=1.884, p=.182, \eta^{2}\right.$ $=.068)$ and $\mathrm{PbL}\left(\mathrm{F}=1.124, \mathrm{p}=.298, \eta^{2}=.040\right)$ respectively did not significantly differ over learning achievement in solid geometry. This implied that the observed mean difference in the SGAT scores between the male and the female students in both groups were not statistically significant at .05 alpha level. Silk et al (2009) also found the mean post reasoning test score of the male participants was slightly higher than that of their female counterparts, but gender was not a statistically significant factor in the prediction of the reasoning ability of students. A classroom setting that acknowledges the desire for students to interact, respect for one another, and sustains a high learning expectations for students is unlikely to have gender disparity in the learning achievement of students. Mehalik, Doppelt, and Schunn (2008) also established that male students adopting the DBL model had significant gains in learning in comparison to their counterparts who used scripted inquiry model. The male and the female students in the DBL group had nearly identical mean learning gain, showing that the DBL model does not yield any gender-based achievement gaps. The achievement gains 
of the female students was higher for the DBL model however, there was no significant difference in the science achievement scores between the male and the female students in DBL group.

\section{Conclusion}

The Design-Based Learning model has proven its superiority over Problem-based Learning model in the improvement of the learning achievement of students in solid geometry. However, both instructional models were capable of enhancing students' learning achievement over time irrespective of their gender. Specifically, the DBL model was more favourable to the male students whereas the $\mathrm{PbL}$ favoured the female students more than their male counterparts in terms of learning achievement in solid geometry. However the observed gender inequity in SGAT scores was not statistically significant. The implication of the present finding is that mathematics educators and policy makers will appreciate the importance of DBL in achieving enhanced learning achievement in solid geometry among senior secondary students in Nigeria. This is because DBL is useful in advancing the $4 \mathrm{Cs}$ of $21^{\text {st }}$ century education skills of the students viz: critical thinking, creativity, effective communication and collaborative skills.

\section{Recommendations}

Based on the findings of the present study the following recommendations were made:

1. Mathematics teacher should apply the DBL in teaching solid geometry in the senior secondary schools in Nigeria because when effectively utilized, this instructional model is capable of advancing the learning achievement of students in mathematics irrespective of their locations.

2. Both the male and the female students should be engaged equally while learning. They should be given the opportunity to interact, share ideas and respect their peers during learning episode for the elimination of gender inequity in mathematics education.

\section{References:}

1. Apedoe, X., B. Reynolds, M. R. Ellefson, \& Schunn, C.D.. (2008). Bringing engineering design into high school science classrooms: The heating/cooling unit. Journal of Science Education and Technology 17(5), $454-465$.

2. Apedoe, X., Ellefson, M.E. \& Schunn, C.D. (2012). Learning together while designing: Does group size make a difference? Journal of Science Education and Technology, 21(1): 83-94. 
3. Apedoe, X.S. \& Schunn, C.D. (2012). Strategies for success: Uncovering what makes students successful in design and learning. Instructional Science, 41 (4), 773-791. ISSN 0020-4277.

4. Barron B.J.S, Schwartz DL, Vye NJ, Moore A, Petrosino A, Zech L, Bransford JD, The Cognition Technology Group at Vanderbilt (1998) Doing with understanding: lessons from research on problem-and project-based learning. J Learn Sci 7(3/4):271-311.

5. Doppelt, Y; Mehalik, M.M; Schunn C.D., Silk, E, \& Krysinski, D (2008). Engagement and achievements: A case study of design-based learning in a science context. Journal of Technology Education 19 (2), 22-39.

6. Kolodner, J. L. (2002). Facilitating the learning of design practices: Lessons learned from an inquiry into science education. Journal of Industrial Teacher Education, 39(3), 1-31.

7. Lee, H. \& Breitenberg, M. (2010). Education in the New Millennium: The case for design-based learning. International Journal of Art \& Design Education.29(1).

8. Lewis T (2006) Design and inquiry: bases for an accommodation between science and technology education in the curriculum? J Res Sci Teach 43(3):255-281.

9. Okereke, S.C. (2006). Effect of prior knowledge of implementing of mathematical task/concepts to career type and gender on student's achievement interest and retention. In U. Nzewi (Ed) STAN proceedings of the $47^{\text {th }}$ Annual Conference, 253-259.

10. Orhan, A. \& Ruham, O.T. (2007). The effect of problem based active learning in science education on student's academic achievement, attitude and concept learning. Eurasia Journal of Mathematics, Science \& Technology Education 3(1), 81-81.

11. Rivers State Senior Secondary Schools Board (2015). Students Enrolment for Third Term 2014/2015 academic session.

12. Seng, C. (2001). Problem based learning-educational tool or philosophy. University of Newcastle, Australia.

13. Silk E. M, Schunn, C.D. \& Cary M.S (2009). The impact of an engineering design curriculum on science reasoning in an urban setting. Journal of Science Education and Technology 18(3) 209223.

14. Tick, A. (2007). Application of problem-based learning in classroom activities and multimedia. $5^{\text {th }}$ Slovakian Hungarian joint symposium on applied machine intelligence. 